\title{
Motor Activity Log-Brazil: reliability and relationships with motor impairments in individuals with chronic stroke
}

\author{
Motor Activity Log-Brasil: confiabilidade e relações com a função motora em \\ indivíduos com acidente vascular cerebral crônico
}

Natalia Duarte Pereira1, Angélica Cristiane Ovando', Stella Maris Michaelsen², Sarah Monteiro dos Anjos³, Renata Cristina Magalhães Lima4, Lucas Rodrigues Nascimento4, Luci Fuscaldi Teixeira-Salmela ${ }^{5}$

\begin{abstract}
The Motor Activity Log (MAL) assesses the spontaneous use of the most affected upper limb with the amount of use (AOU) and quality of movement (QOM) scales during daily activities in real environments in individuals with chronic stroke. Objectives: This study translated the testing manual into Portuguese and assessed the inter-rater and test-retest reliabilities of the MAL, based upon the Brazilian manual version. Methods: The inter-rater reliability was evaluated by comparing the results of two examiners, and the test-retest reliability was tested by comparing the results of two evaluations, repeated one-week apart with 30 individuals with chronic hemiparesis (55.8 \pm 15.1 years). Results: The intra-class correlation coefficients (ICCS) for the total scores were adequate for both the inter-rater (0.98 for the AOU and 0.91 for QOM) and test-retest reliabilities (0.99 for both scales). Conclusions: The results suggested that the MAL was reliable to evaluate the spontaneous use of the most affected upper limb after stroke.
\end{abstract}

Key words: stroke, hemiplegia, quality of movement, motor impairment.

\section{RESUMO}

O Motor Activity Log (MAL) avalia o uso espontâneo do membro superior mais afetado por meio da escala de quantidade (EQT) e qualidade (EQL) de uso nas atividades cotidianas em ambiente real em pacientes com acidente vascular cerebral crônico. Objetivo: Este estudo traduziu para o português o manual de aplicação e testou a confiabilidade interavaliadores e teste-reteste do MAL com base na versão brasileira do manual. Métodos: Participaram 30 indivíduos (55,8 $\pm 15,1$ anos) com hemiparesia crônica. A confiabilidade interavaliadores foi testada comparando o resultado de dois avaliadores, e a confiabilidade teste-reteste, pela comparação dos resultados de duas avaliações de um mesmo avaliador, todas com intervalo de uma semana. Resultados: As confiabilidades interavaliadores (coeficiente de correlação intraclasse - $\mathrm{CCl}=0,98$ para a EQT e 0,91 para a EQL) e teste-reteste (CCl=0,99 para ambas as escalas) para os escores totais foram adequadas. Conclusões: A versão brasileira do MAL demonstrou confiabilidade adequada para avaliar o uso espontâneo do membro superior parético depois de um acidente cerebral vascular.

Palavras-Chave: acidente cerebral vascular, hemiplegia, qualidade de movimento, função motora.

It is estimated that approximately $70 \%$ of individuals with hemiparesis following stroke with upper limb (UL) dysfunctions remain with residual disabilities ${ }^{1-4}$. These deficits are mainly characterized by slower reaching and grasping movements, excessive compensatory trunk movements and reduced gross and fine manual dexterity ${ }^{5,6}$. After two to four years after stroke, about 50 to $70 \%$ of the survivors demonstrate some resulting UL dysfunctions with functional losses and non-use of the paretic UL?

Despite the large number of interventions designed to improve the motor ability of the most affected UL, studies have typically evaluated the UL function using measures which are

\footnotetext{
1 Mestre em Ciências do Movimento Humano, Universidade do Estado de Santa Catarina (UDESC), Florianópolis SC, Brazil;

${ }^{2}$ Doutora, Docente dos Programas de Pós-graduação (PPG) em Ciências do Movimento Humano e de Fisioterapia, UDESC, Florianópolis SC, Brazil;

${ }^{3}$ Mestranda do Programa de Pós-graduação do Departamento de Neurologia da Faculdade de Medicina da Universidade de São Paulo (FMUSP), São Paulo SP, Brazil;

${ }^{4}$ Mestre e Doutorando em Ciências da Reabilitação, Universidade Federal de Minas Gerais (UFMG), Belo Horizonte MG, Brazil;

${ }^{5}$ Doutora, Docente do Programa de Pós-graduação em Ciências da Reabilitação, UFMG, Belo Horizonte MG, Brazil.

Correspondence: Natalia Duarte Pereira; Programa de Pós-Graduação em Ciências do Movimento Humano - CEFID/UDESC; Rua Pascoal Simone 358; 88080-350 Florianópolis SC - Brasil; E-mail: nat_duarte@yahoo.com.br

Conflict of interest: There is no conflict of interest to declare.
}

Received 09 May 2011; Received in final form 13 September 2011; Accepted 20 September 2011 
specific to body structures and functions and/or global measures of activity and participation within laboratory or clinical environments ${ }^{8}$. However, motor ability and the use of the UL in this context may not correspond to what the individuals really perform in their daily lives. Thus, it is important to rely on adequate instruments to assess relevant aspects of functional performance in real life contexts ${ }^{9}$. The effects of neurorehabilitation on the most affected UL use in the real world are largely unexamined, and deficits in the most affected UL use after neurological injuries may be underdiagnosed ${ }^{8}$.

To evaluate the actual spontaneous use of the most affected UL during activities outside of the treatment settings, the Motor Activity Log (MAL) was developed. The MAL is composed of quantitative and qualitative scales and is administered by structured interviews during which patients are asked to rate how much, the amount of use (AOU), and how well, the quality of movement (QOM), their most impaired arm was used to accomplish each of the 30 activities of daily living ${ }^{8,10}$.

The MAL was developed by Taub et al. ${ }^{10}$ to evaluate the effects of constraint-induced movement therapy on the use of the most affected UL in individuals with stroke ${ }^{11}$. Its original version was composed of 14 items $^{8}$. Subsequently, to allow the assessment of individuals with greater impairments, a 30 -item version was developed ${ }^{11,12}$, which was evaluated regarding its internal consistency, test-retest reliability and convergent validity. A summary of the psychometric properties of the MAL was previously reported by a systematic review of the literature ${ }^{13}$. The 30 -item MAL was translated and transculturally adapted to the Brazilian Portuguese language and some of its psychometric properties were evaluated with Rasch analyses. The MAL-Brazil demonstrated to be clinically useful to assess the use of most affected UL of adults with chronic hemiparesis ${ }^{13}$. However, the process of adaptation and translation does not assure the preservation of the psychometric properties of the original version of the instrument and, thus, the reliability of the translated and transculturally adapted version should be evaluated.

Although Saliba et al. ${ }^{13}$ found adequate test-retest reliability, they did not report the test-retest reliability for the individual items and did not evaluate the inter-rater reliability of the Brazilian version. Since the reliability of the translated version of the MAL and the testing manual in the Portuguese language have not been evaluated, and considering the importance of systematic assessments to inform the effects of neurorehabilitation on the most affected UL use in the real world, the aims of the present study were: to evaluate the reliability of the MAL, based upon the Brazilian version of the testing manual, and the relationships between the scores obtained from self-evaluation interviews regarding the AOU and QOM of the most affected UL and those obtained by the performance-based scale.

\section{METHODS}

\section{Initial translation of the MAL testing manual}

The present study used the items of the Brazilian version of the MAL ${ }^{13}$. The testing manual was translated by two Brazilian physical therapists, who were fluent in English and aware of the research objectives. They received training regarding the MAL administration by the group of authors of the latest version of the test at the University of Alabama, United States.

\section{MAL administration}

The MAL is a structured interview, in which patients are asked to rate how much (AOU scale) and how well (QOM scale) their most affected arm was used to accomplish 30 activities of daily living outside of the therapeutic environment. The interview was conducted according to standardized procedures described in the testing manual. Both scales, AOU and QOM, were printed on separate forms, which were placed in front of the participants during the test administration.

Both MAL scales are scored on six points, ranging from zero (never used) to five (the same as pre-stroke), and participants may select halfway scores, such as 1.5. Before its administration, the differences between the AOU and QOM scales were explained in detail and, during the test administration, these differences were emphasized at regular intervals.

Each time the participants selected their scores, the interviewer verified their answers by reading out loudly the chosen scores, so that they could confirm their choices, according to the testing manual instructions. Each scale total score corresponds to the mean of the items, calculated by the sum of the scores of all items, divided by the number of the accomplished items.

\section{Participants}

The translation of the testing manual and the participants' assessments were carried out after the study approval by the University Ethical review board (\#214/2009) and all participants provide written informed consent.

Thirty individuals (55.8 \pm 15.1 years) with chronic hemiparesis (35.7 \pm 35.2 months after the onset of their stroke) were recruited from the general community of the cities of Belo Horizonte and Florianópolis, Brazil. All participants were in regular physical therapy treatment for at least six months. Fifteen participated in the test-retest and the other 15 in the inter-rater reliability measurements. Both samples were homogeneous regarding their ages, UL motor impairments, according to the Fugl-Meyer (FM) UL scores ${ }^{14}$, MiniMental Status Examination scores ${ }^{15}$, and limb dominance. Participants of the inter-rater group were predominantly men and were more chronic, with differences of 16.1 months since the onset of their stroke. 
To be included, the participants should have been at least 18 years old, had more than six months since the onset of their stroke and had no cognitive deficits, as determined by their Mini-Mental Status Examination scores ${ }^{15}$. Participants were excluded if they had severe cognitive deficits, receptive aphasia, other neurological diseases, complete UL motor recovery $(\mathrm{FM} \geq 65)$ or were completely plegic.

\section{Test-retest and inter-rater reliabilities of the MAL based upon the testing manual information}

To examine the test-retest reliability, one examiner, who was not familiar with the interview administration (LRN), applied the test twice, within one-week apart, based upon the testing manual information. The interrater reliability was evaluated by two independent raters (ACO and NDP), one of them received training at the University of Alabama (NDP) and the other only had access to the translated testing manual. Subjects were tested by both raters approximately one-week apart ${ }^{13,16}$. The decision to choose examiners, who were familiar and not familiar with the interview administration, was necessary to guarantee that the information described in the manual was sufficient to guide examiners and clinicians during clinical applications.

\section{Statistical analyses}

Intra-class correlation coefficients (ICCs) and their associated 95\% confidence intervals (CIs) were used to estimate the inter- and test-retest reliabilities for the AOU and QOM scales. The ICC values were classified as poor $(<0.4)$, good $(0.4<\mathrm{CCI}<0.75)$ and excellent $(>0.75)^{17}$. Spearman rank correlation coefficients were calculated to evaluate the relationships between the MAL scores and the motor impairment levels (FM scores), whereas the Bland and Altman ${ }^{18}$ method was used to evaluate the test-retest and inter-rater agreements. The upper and lower limits of agreement represented the "error thresholds ${ }^{18}$. For all analyses, the significance level was established at $5 \%$.

\section{RESULTS}

\section{Participants characteristics}

The participants were predominantly men (66.6\%). Twelve (40\%) had motor impairments classified as mild (FM>50), eight $(26.7 \%)$ as moderate (FM between 30 and 49$)$ and ten $(33.3 \%)$ had serious motor impairments $(\mathrm{FM}<30)^{14}$. Their Mini-Mental Status Examination scores ranged from 20 to 30 , and $56.6 \%$ had left hemiparesis. Regarding dominance, $86.6 \%$ were right-handed and $43.3 \%$ of the participants had paresis of their dominant UL. Table 1 gives the demographic and clinical information of the participants.
Table 1. Demographic, stroke-related and clinical characteristics of the participants $(n=30)$.

\begin{tabular}{lc} 
Variable & Result \\
\hline Age (years), mean (SD) & $55.8(15.1)$ \\
Time since stroke (years), mean (SD) & $35.7(35.2)$ \\
Gender (Men/Women), $n$ & $20 / 10$ \\
Affected side (Right/Left), & $13 / 17$ \\
Dominance (Right/Left), $n$ & $26 / 4$ \\
Fugl-Meyer - Upper limb score (0-66), mean (SD) & $38.1(21.1)$ \\
Mini-Mental State Examination Score (0-30), & $25.4(3.8)$ \\
mean (SD) &
\end{tabular}

\section{Reliability}

The total scores for the AOU and QOM scales regarding the test-retest reliability are shown in Table 2 . The ICCs for the 29 tasks of the AOU scale were considered excellent (>0.94). Only the item related to the use of a TV remote control had an ICC of 0.77 , although it was also considered excellent. This same item together with the one related to turning on a light with a switch had ICCs considered as good (0.63 and 0.68, respectively) for the QOM scale. The ICCs for the total scores were above 0.99 for both scales. The Bland and Altman plots illustrating the test-retest agreement are shown in Figure. The mean differences between the two measurements did not significantly differ from zero, and the limits of agreement were less than $5 \%$ of the range for both scales.

The ICCs for the AOU regarding the inter-rater reliability ranged from 0.83 to 0.99 , and the lowest ICC was found for the "wipe off a kitchen counter" item, which was considered excellent. The item-total reliability coefficient for the AOU scale was excellent (ICC=0.98) with ICCs ranging from 0.97 to 0.99 . The lowest ICC for the QOM scale was found for the item "turn on a light with a light switch" (0.76) (Table 2). The Bland and Altman plots illustrating the interrater agreement showed that the mean differences between the two measurements did not differ significantly from 0 and the limits of agreement were less than $10 \%$ of the range of the scale for the AOU scale. The limits of agreement for the QOM scales were 8.4 and $14 \%$ of the range of the scale.

\section{Correlations between the MAL and the motor impairment scores}

The Spearman's correlation coefficients between the total AOU and FM scores for raters one and two were 0.76 $(\mathrm{p}<0.001)$ and $0.77(\mathrm{p}<0.001)$, respectively. Likewise, the total QOM scores correlated with the FM scores for both raters $(\rho=0.78$ and $0.80 ; p<0.001)$. When the most affected participants $(\mathrm{FM}<30)$ were excluded, positive correlations $(\mathrm{n}=19)$ were found between the total AOU and FM scores for rater one $(\rho=0.54, p=0.02)$ and two $(\rho=0.47, p=0.04)$. Similarly, the total QOM correlated with the FM scores for the two raters $(\rho=0.54$ and $0.53, p=0.02)$. 
Table 2. Intra-class correlation coefficients (ICCs) and 95\% confidence intervals (Cls) for the test-retest and inter-rater reliabilities for the amount of use (AOU) and quality of the movement (QOM) for the individual items of the Brazilian version of the Motor Activity Log (MAL-Brazil).

\begin{tabular}{|c|c|c|c|c|}
\hline \multirow[t]{2}{*}{ Item } & \multicolumn{2}{|c|}{$\begin{array}{l}\text { Inter-rater } \\
\text { ICC }(95 \% \mathrm{Cl})\end{array}$} & \multicolumn{2}{|c|}{$\begin{array}{l}\text { Test-retest } \\
\text { ICC }(95 \% \mathrm{CI})\end{array}$} \\
\hline & $\mathrm{AOU}$ & QOM & $\mathrm{AOU}$ & QOM \\
\hline Turn on a light with a light switch & $0.95(0.85-0.98)$ & $0.76(0.30-0.92)$ & $0.95(0.86-0.98)$ & $0.68(0.35-0.89)$ \\
\hline Open a drawer & $0.99(0.97-0.99)$ & $0.89(0.69-0.96)$ & $0.94(0.82-0.98)$ & $0.98(0.93-0.99)$ \\
\hline Remove an item of clothing from a drawer & $0.93(0.79-0.97)$ & $0.97(0.91-0.99)$ & $0.97(0.91-0.99)$ & $0.99(0.98-0.99)$ \\
\hline Pick up a phone & $0.97(0.91-0.99)$ & $0.96(0.88-0.99)$ & $0.99(0.98-0.99)$ & $0.99(0.98-0.99)$ \\
\hline Wipe off a kitchen counter or another surface & $0.83(0.48-0.94)$ & $0.89(0.68-0.96)$ & $0.98(0.95-0.99)$ & $0.99(0.98-0.99)$ \\
\hline Get out of a car & $0.96(0.87-0.98)$ & $0.88(0.63-0.96)$ & $0.97(0.91-0.99)$ & $0.94(0.82-0.98)$ \\
\hline Open a refrigerator & $0.95(0.86-0.98)$ & $0.91(0.74-0.97)$ & $0.99(0.98-0.99)$ & $0.99(0.97-0.99)$ \\
\hline Open a door by turning a door knob & $0.95(0.86-0.98)$ & $0.93(0.80-0.98)$ & $0.97(0.90-0.98)$ & $0.96(0.89-0.99)$ \\
\hline Use a TV remote control & $0.92(0.76-0.97)$ & $0.98(0.93-0.99)$ & $0.77(0.30-0.92)$ & $0.63(-0.1-0.88)$ \\
\hline Wash your hands & $0.90(0.71-0.97)$ & $0.96(0.88-0.98)$ & $0.99(0.99-0.99)$ & $0.98(0.96-0.99)$ \\
\hline Turning water on/off with a knob/lever on faucet & $0.96(0.87-0.98)$ & $0.99(0.97-0.99)$ & $0.97(0.91-0.99)$ & $0.98(0.95-0.99)$ \\
\hline Dry your hands & $0.92(0.75-0.97)$ & $0.93(0.79-0.98)$ & $0.96(0.88-0.98)$ & $0.97(0.92-0.99)$ \\
\hline Put on your socks & $0.96(0.89-0.98)$ & $0.92(0.77-0.97)$ & $0.98(0.94-0.99)$ & $0.96(0.89-0.99)$ \\
\hline Take off your socks & $0.99(0.99-0.99)$ & $0.92(0.77-0.97)$ & $0.99(0.99-0.99)$ & $0.99(0.99-0.99)$ \\
\hline Put on your shoes & $0.99(0.98-0.99)$ & $0.94(0.83-0.98)$ & $0.98(0.94-0.99)$ & $0.99(0.99-100)$ \\
\hline Take off your shoes & $0.99(0.97-0.99)$ & $0.87(0.62-0.96)$ & $0.95(0.86-0.98)$ & $0.99(0.97-0.99)$ \\
\hline Get up from a chair with arm rests & $0.96(0.88-0.98)$ & $0.97(0.92-0.99)$ & $0.98(0.96-0.99)$ & $0.99(0.97-0.99)$ \\
\hline Pull a chair away from the table before sitting down & $0.97(0.91-0.99)$ & $0.95(0.87-0.97)$ & $0.99(0.96-0.99)$ & $0.99(0.99-100)$ \\
\hline Pull chair toward table after sitting down & $0.91(0.71-0.97)$ & $0.88(0.66-0.96)$ & $0.99(0.97-0.99)$ & $0.99(0.98-0.99)$ \\
\hline Pick up a glass, bottle, drinking cup or can & $0.97(0.91-0.99)$ & $0.97(0.91-0.99)$ & $0.97(0.92-0.99)$ & $0.96(0.89-0.98)$ \\
\hline Brush your teeth & $0.98(0.95-0.99)$ & $0.97(0.90-0.99)$ & $0.98(0.97-0.99)$ & $0.99(0.99-0.99)$ \\
\hline Put on makeup, Lotion, or shaving cream on face & $0.89(0.69-0.96)$ & $0.96(0.89-0.99)$ & $0.97(0.92-0.99)$ & $0.86(0.59-0.95)$ \\
\hline Use a key to unlock a door & $0.99(0.98-0.99)$ & $0.99(0.98-0.99)$ & $0.99(0.97-0.99)$ & $100(100-100)$ \\
\hline Write on paper & $0.97(0.76-0.99)$ & $0.89(0.69-0.96)$ & $0.92(0.28-0.99)$ & $100(100-100)$ \\
\hline Carry an object in your hand & $0.88(0.66-0.96)$ & $0.87(0.62-0.96)$ & $0.96(0.90-0.99)$ & $0.99(0.97-0.99)$ \\
\hline Use a fork or spoon for eating & $0.97(0.91-0.99)$ & $0.80(0.39-0.93)$ & $0.99(0.98-0.99)$ & $0.97(0.91-0.99)$ \\
\hline Comb your hair & $0.99(0.99-0.99)$ & $0.99(0.97-0.99)$ & $0.98(0.96-0.99)$ & $0.99(0.99-100)$ \\
\hline Pick up a cup by the handle & $0.98(0.93-0.99)$ & $0.92(0.77-0.97)$ & $0.99(0.99-0.99)$ & $0.99(0.98-0.99)$ \\
\hline Button a shirt & $0.99(0.97-0.99)$ & $0.91(0.72-0.97)$ & $0.99(0.97-0.99)$ & $0.97(0.91-0.99)$ \\
\hline Eat half a sandwich or finger foods & $0.95(0.86-0.98)$ & $0.96(0.89-0.98)$ & $0.99(0.97-0.99)$ & $0.98(0.95-0.99)$ \\
\hline Total & $0.98(0.97-0.99)$ & $0.91(0.75-0.97)$ & $0.99(0.99-0.99)$ & $0.99(0.99-0.99)$ \\
\hline Mean score (SD) test-rest & $1.47(1.26)$ & $1.52(1.27)$ & $1.49(1.26)$ & $1.59(1.31)$ \\
\hline Mean score (SD) interrater & $1.46(1.57)$ & $1.32(1.36)$ & $1.44(1.55)$ & $1.18(1.34)$ \\
\hline
\end{tabular}

All items with $p<0.05$.

\section{DISCUSSION}

The present study evaluated the reliability of the Brazilian version of the MAL accompanied by the translated testing manual, and the results for the inter-rater and test-retest reliabilities were adequate. The second objective was to evaluate the relationships between the scores obtained from self-evaluation interviews regarding the AOU and QOM of the most affected UL and those obtained by the performance-based scale, which evaluates post-stroke motor impairments.

The ICCs regarding the test-retest reliability were superior to those reported in previous studies, which assessed testretest reliability with the original scale ${ }^{8,12,16}$, although both can be considered excellent ${ }^{17}$. This difference may have occurred due to distinct inclusion criteria, since for the reliability studies with the original scale the participants should have been able to actively abduct their thumbs and extend their wrists and two or more digits more than ten degrees, which characterizes highly functioning individuals ${ }^{8,12,16}$. On the other hand, the present study included individuals with all levels of motor impairments, which can be observed by their Fulg-Meyer scores, ranging from four to 64 . Considering that approximately $2 / 3$ of the MAL items require finger movements ${ }^{12}$, the probability of variations in scale rankings is higher in individuals with less UL motor impairments, compared to those with low functioning, who can more often score one or zero. 
A

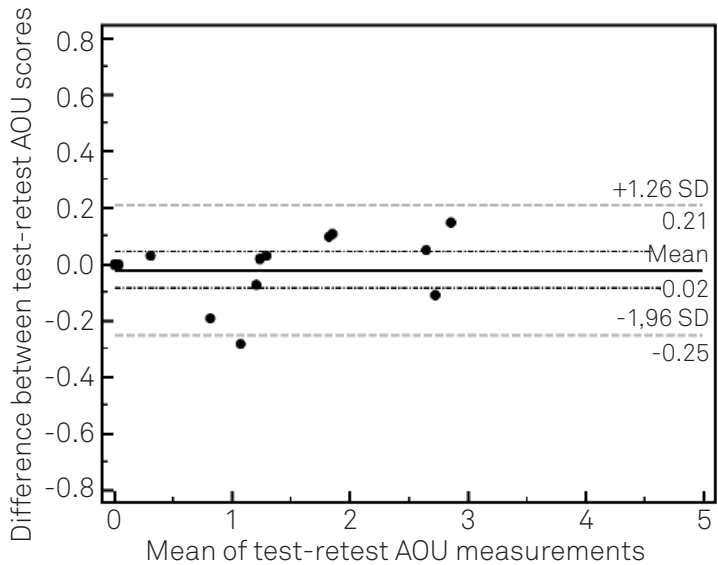

C

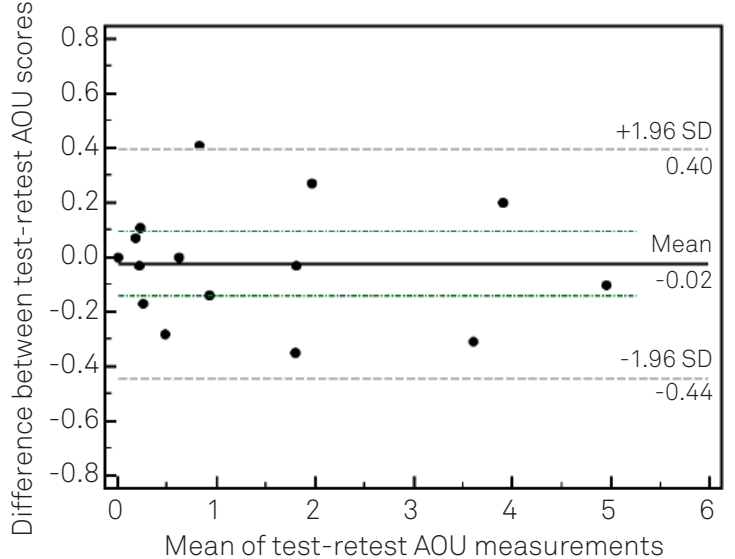

B

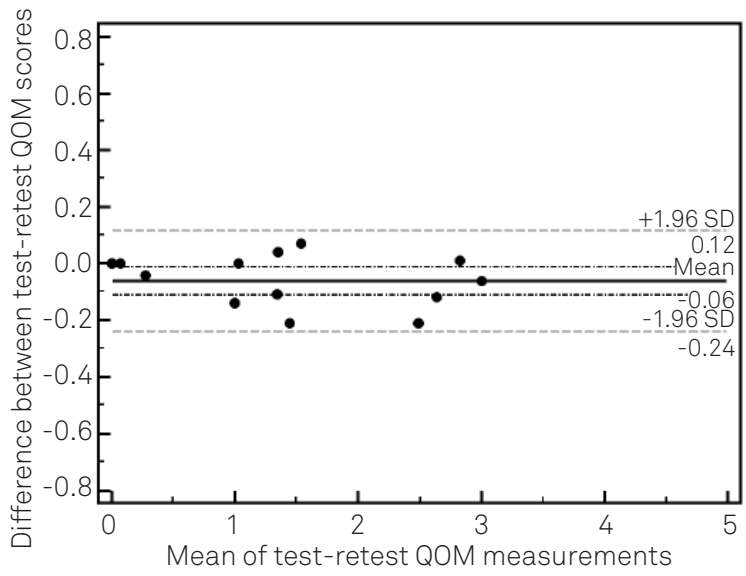

D

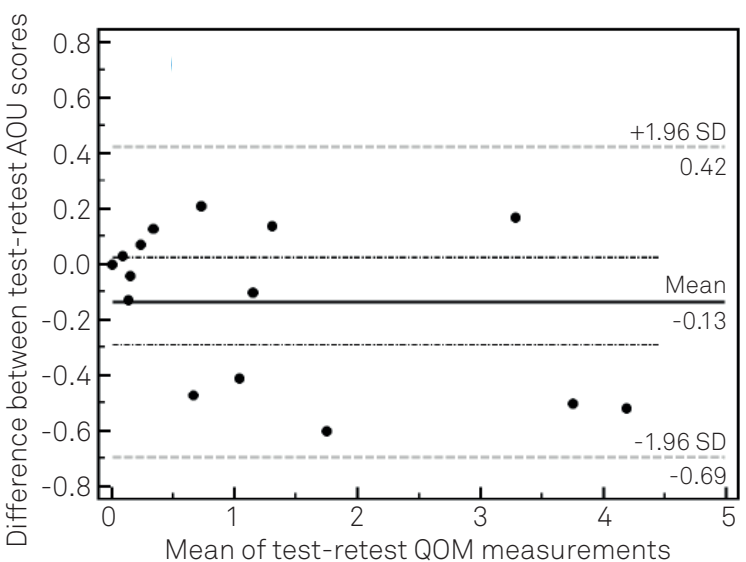

Figure. Scatter plots of the differences between the MAL amount of use (AOU) and quality of movement (QOM) scores and the mean of total scores per individual. (A) and (B): Test-retest scores for the AOU and QOM scales. (C) and (D): Inter-rater scores for the AOU and QOM scales. The horizontal continuous black lines in the middle indicate the mean differences and their confidence intervals are shown by black dotted lines. The gray dotted lines (more distant) indicate the upper and lower limits of agreement.

Previous studies adopted the minimal clinically important difference (MCID) set at $10 \%$ of the scale range, i.e., 0.5 points $^{12,16}$, to demonstrate clinical improvements. While this proposed value may have been a good starting point to demonstrate improvements, there is no consensus in the literature regarding the responsiveness of the MAL to show improvements in the UL function ${ }^{19}$. In the present study, the mean test-retest differences for both AOU and QOM scales were 0.08 and 0.07 , respectively, which were lower than the established clinically relevant limits. Observations of the mean differences between the test-retest measurements on the scatter plots showed that they did not exceed 0.5 points (Figure), except for one participant who showed an inter-rater difference of 0.6 points for the QOM scale. The test-retest agreement demonstrated that the MAL was stable for these individuals with chronic stroke, with limits of agreement less than $5 \%$ of the scale range for both the AOU and QOM scales. Regarding the inter-rater evaluations, the present results demonstrated that the mean differences were respectively 0.2 and 0.3 for the AOU and QOM, which also did not exceed the adopted MCID.

When considering the inter-rater scores for the QOM scale, the scatter plot showed that changes should be above
$14 \%$ of the scale range to exceed the measurement errors. This means that the reproducibility of the MAL scores by the same rater might be sufficient to detect changes of $10 \%$ of the scale range, which was proposed as the MCID, but this is unclear when different raters evaluate the effects of neurorehabilitation at pre- and post-interventions. Despite that the inter-rater reliability for the QOM scale was considered excellent (ICC $=0.91$ ), it is important to follow the testing manual instructions or use strategies, such as video demonstrations with examples of various ranking levels of QOM for some of the MAL items, so that the patients could establish a common point of reference and ensure accurate information.

In this study, individuals who had greater limitations of their UL use also had greater motor impairments, as demonstrated by the positive correlations between the AOU and QOM scores with the FM scores. According to Lang and $\mathrm{Beeb}^{20}$, to be able to use the hand for functional activities, it is necessary to have control of the more proximal UL segments to position and orient the hand with respect to the environment, and may need good control of the fingers to manipulate objects within the environment. They reported 
that the movement control of all segments, as well as hand grip strength and active range of motion, was related to hand function for activities of daily living in chronic stroke individuals. In the present study, it was observed for the MAL items: "use a TV remote control", "pick up a cup by a handle", and "button a shirt" that 15 out of the 20 participants with FM scores $<30$ scored could not perform, i.e., they scored zero on the AOU scale, illustrating the relationships between functionality and fine motor activities.

This study also provided relevant information regarding the profile of the participants who might benefit from the MAL evaluations. Individuals with various motor impairment levels were evaluated and it was observed that the most severely impaired subjects showed floor effects. This may have happened due to the fact that the MAL has few easy items. When the participants with severe motor impairments $(\mathrm{FM}<30)$ were excluded, the correlations between the FM scores and the AOU and QOM scores decreased. Clinically, these results are in accordance with those reported by Saliba ${ }^{13}$ and suggest that the use of the MAL is limited when applied to individuals with severe motor impairments. Otherwise, the scale allows measurement of individuals with superior UL abilities and does not demonstrate ceiling effects.
Some of the limitations of this study included the relatively small sample and the number of raters for the interrater reliability assessments, which could limit the generalizability of the results. However, the inter-rater reliability was considered excellent between the trained and the untrained raters, which suggested that the manual was sufficiently clear to guide the examiners during the test administration. Increased number of raters from different areas of rehabilitation is strongly recommended in future studies to better demonstrate inter-rater reliability.

The Brazilian version of the MAL demonstrated adequate psychometric properties and the potential to be used as a performance measurement of the paretic UL of individuals with mild or moderate motor impairments after stroke since the evaluators follow the manual instructions. Respecting it had shown to be an instrument of high reliability and wide applicability, the MAL should combine the testing manual and the demonstration videos, to illustrate the QOM for measuring the amount and quality of use of the most affected UL of patients with hemiparesis, together with other standardized instruments, to obtain more accurate assessments of the effects of rehabilitation in real life contexts of these individuals.

\section{References}

1. Wolf SL, Thompson PA, Winstein CJ, et al. The EXCITE stroke trial: comparing early and delayed constraint-induced movement therapy. Stroke 2010;41:2309-2315.

2. DromerickAW, Edwards DF, Hahn M. Does the application of constraintinduced movement therapy during acute rehabilitation reduce arm impairment after ischemic stroke? Stroke 2000;31:2984-2988.

3. van der Lee JH, Beckerman H, Lankhorst GJ, Bouter LM. Constraint-induced movement therapy. Arch Phys Med Rehabil 1999;80:1606-1607.

4. Dromerick AW, Lang CE, Birkenmeier RL, et al. Very Early constraintinduced movement during stroke rehabilitation (VECTORS): a singlecenter RCT. Neurology 2009;73:195-201.

5. Broeks JG, Lankhorst GJ, Rumping K, Prevo AJ. The long-term outcome of arm function after stroke: results of a follow-up study. Disabil Rehabil 1999;21:357-364.

6. Michaelsen SM, Jacobs S, Roby-Brami A, Levin MF. Compensation for distal impairments of grasping in adults with hemiparesis. Exp Brain Res 2004;157:162-173.

7. Woldag $H$, Hummelsheim $H$. Evidence-based physiotherapeutic concepts for improving arm and hand function in stroke patients: a review.J Neurol 2002;249:518-528.

8. Uswatte G, Taub E, Morris D, Vignolo M, McCulloch K. Reliability and validity of the upper-extremity Motor Activity Log-14 for measuring real-world arm use. Stroke 2005;36:2493-2496.

9. Ashford S, Slade M, Malaprade F, Turner-Stokes L. Evaluation of functional outcome measures for the hemiparetic upper limb: a systematic review. J Rehabil Med 2008;40:787-795.

10. Taub E, Miller NE, Novack TA, et al. Technique to improve chronic motor deficit after stroke. Arch Phys Med Rehabil 1993;74:347-354.

11. Winstein CJ, Miller JP, Blanton S, et al. Methods for a multisite randomized trial to investigate the effect of constraint-induced movement therapy in improving upper extremity function among adults recovering from a cerebrovascular stroke. Neurorehabil Neural Repair 2003;17:137-152.

12. Uswatte G, Taub E, Morris D, Light K, Thompson PA. The Motor Activity Log-28: assessing daily use of the hemiparetic arm after stroke. Neurology 2006;67:1189-1194.

13. Saliba VA, Magalhães LC, Faria CD, Laurentino GEC, Cassiano JG, Teixeira-Salmela LF. Adaptação transcultural e análise das propriedades psicométricas da versão brasileira do instrumento Motor Activity Log. Rev Panam Salud Publica 2011;30:262-271.

14. Michaelsen SM, Rocha AS, Knabben RJ, Rodrigues LP, Fernandes CGC. Tradução, adaptação e confiabilidade interexaminadores do manual de administração da escala de Fugl-Meyer. Rev bras fisioter 2011;15:80-88.

15. Bertolucci P, Brucki SMD, Campacci SR, Juliano Y. O mini-exame do estado mental em uma população geral: impacto da escolaridade. Arq Neuropsiquiatr 1994;52:1-7.

16. van der Lee JH, Beckerman H, Knol DL, de Vet HC, Bouter LM. Clinimetric properties of the motor activity log for the assessment of arm use in hemiparetic patients. Stroke 2004;35:1410-1414.

17. Fleiss Jl. Statistical methods for rates \& proportions. New York: Wiley and Sons; 2004.

18. Bland JM, Altman DG. Statistical methods for assessing agreement between two methods of clinical measurement. Lancet 1986; 1:307-310.

19. Fritz SL, George SZ, Wolf SL, Light KE. Participant perception of recovery as criterion to establish importance of improvement for constraint-induced movement therapy outcome measures: a preliminary study. Phys Ther 2007;87:170-178.

20. Lang CE, Beebe JA. Relating movement control at 9 upper extremity segments to loss of hand function in people with chronic hemiparesis. Neurorehabil Neural Repair 2007;21:279-291. 